\title{
Medical aspects of the work of a moorland rescue team
}

\author{
H R Guly
}

\begin{abstract}
Objective-To describe the work of a moorland rescue team and, in particular, the medical aspects of this work.

Methods-A retrospective study of 25 years of callouts of the Dartmoor Rescue Group (DRG)-the mountain rescue team (MRT) for Dartmoor. These were analysed by cause, year, month, day of the week, and time of day. Injuries and other medical problems in casualties are described.
\end{abstract}

Results-276 callouts are described. The most common cause was searching for missing persons, but 62 callouts were to known casualties. The most common medical problem was cold exhaustion. The most common injuries were to the lower leg. However, a wide variety of other medical problems including heat exhaustion was also seen.

Conclusions-The Mountain Rescue Council represents MRTs in mountainous regions and those covering lower hills and moorland. It produces an annual report containing details of the incidents attended by its affiliated teams. The work of the DRG is very different from that of the Mountain Rescue Council as a whole. Medical problems other than cold exhaustion and lower leg injuries are uncommon and moorland rescue teams do not need to equip themselves to treat other medical problems but in view of the wide variety of medical problems encountered a long way from a road, good first aid training of team members is essential.

(Brf Sports Med 1996;30:260-263)

Most sportsmen who suffer an acute injury can receive immediate care and for those with more severe injuries, there is usually little difficulty in transporting them to hospital. Things are more difficult for the walker or climber who injures himself perhaps several miles from the nearest road. In these circumstances first aid and evacuation is frequently done by mountain rescue teams (MRTs).

The Dartmoor Rescue Group (DRG) was

Accident an

Emergency

Department, Derriford Hospital, Plymouth PL6 8DH, United Kingdom H R Guly

Correspondence to: H R Guly FRCP FFAEM

Accepted for publication 14 March 1996 the MRT for the area. It currently has four sections based in Tavistock, Plymouth, Okehampton, and Ashburton. For any callout, one or more sections will be mobilised, depending on the nature and location of the incident and the number of casualties.

\section{Methods}

A retrospective study was performed of the work of the DRG from 1968 to 1992 . Information was obtained from details of callouts notified to the Mountain Rescue Council. Further details were obtained from minutes of debriefings, some press reports, and (when available) accident and emergency records. It includes callouts on Dartmoor, incidents discovered by DRG teams while on exercise, and incidents when DRG teams or search dogs and handlers were called to incidents off the moor. It excludes incidents when DRG teams, exercising elsewhere in the country, assisted other MRTs. In some cases the DRG was called but not deployed, for example if the casualty was found by helicopter or walked off by themselves.

The DRG also provides safety cover for some organised events on Dartmoor. The biggest is the Ten Tors expedition in which up to 2400 young people undertake routes of 35,45 , or 55 miles on the moor with an overnight camp. The DRG records relating to work done for this from 1983 to 1992 have been examined. Not all of these involve rescues as some of the casualties will have reported to DRG aid posts on the moor.

\section{Results}

The DRG was called out 276 times from 1967 to 1992 . In 231 callouts teams were deployed on the ground. Seventeen were not on Dartmoor (most of these were within Devon). Unfortunately many of the records (especially in the early years) are incomplete. Where tables have been produced from incomplete data, the number of observations on which the data are based is stated. As the records were kept primarily for supplying statistical data to the Mountain Rescue Council many medical details including whether or not casualties were taken to hospital or were admitted are lacking.

Figure 1 shows the number of callouts by year. There appear to have been no callouts in 1975. Figures 2, 3, and 4 show the number of callouts by month, by day and by the time of the day the callout was initiated.

The reasons for the callouts are shown in table 1 .

The medical problems of casualties are shown in table 2 . In many cases with cold exhaustion there was more than one person 


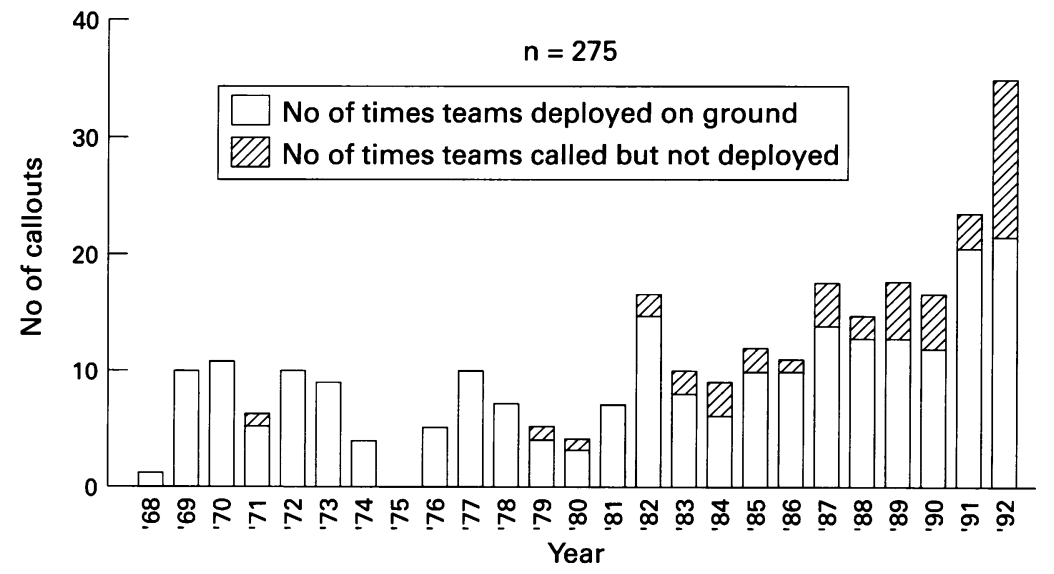

Figure 1 Callouts by year.

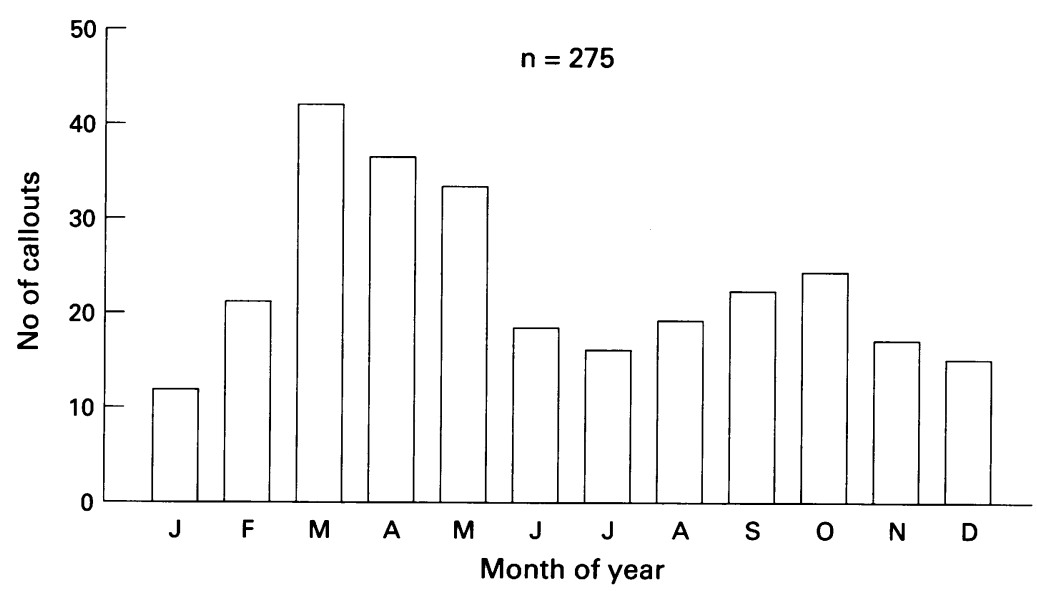

Figure 2 Callouts by month.

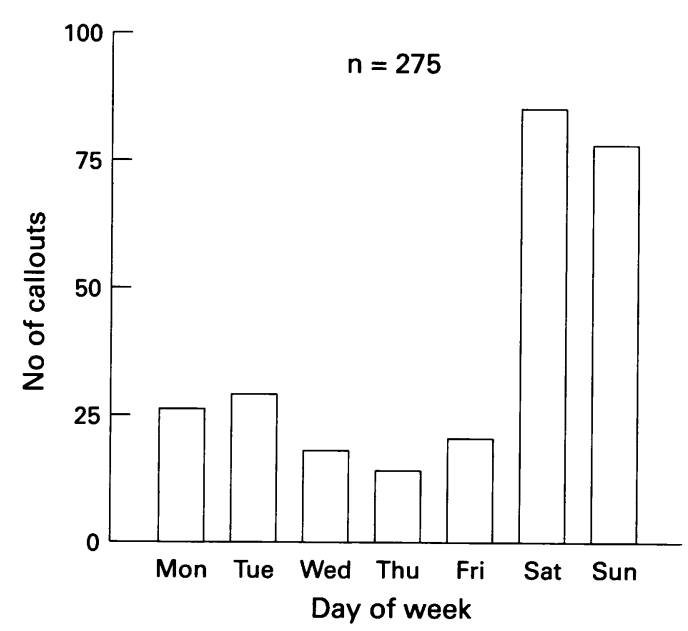

Figure 3 Callouts by day.

involved (on one occasion 17) and on at least two occasions there were three casualties, all sufficiently ill to require a stretcher.

Table 3 shows the medical problems of those known to have been admitted to hospital. This is almost certainly an underestimate because of incomplete records. It excludes 10 inpatients from psychiatric hospitals who went missing and who were returned to hospital once found.

There were 16 incidents involving deaths. Eleven of these were on Dartmoor. The commonest causes of death were ischaemic heart disease and suicide. Table 4 shows the casualties dealt with by the DRG in the Ten Tors expeditions.

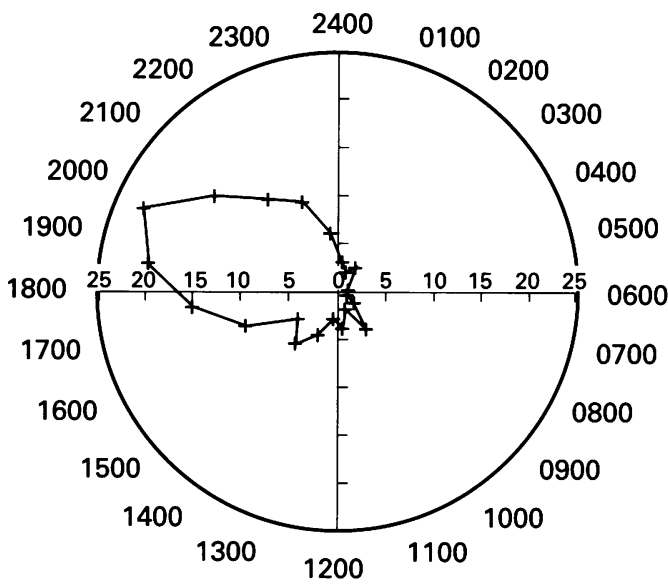

Figure 4 Callouts by time of initiation $-24 h$ clock ( $n=$ 154)

Table 1 Reason for callout

Searches

Person(s) failed to return from walk etc 124

$\begin{array}{ll}\text { Person missing from home/hospital } & 40 \\ \text { Horse rider failed to return } & 2\end{array}$

Horse rider failed to return $\quad 2$

Indication that person was lost (eg flares seen,

Search for dead bodies (SARDA only)

Other searches (eg lost farm worker, children 5

run away)

Search reason not stated 6

Total searches $\quad 190$

Known casualty

Animal rescue

Recovery of dead body

Stuck rock climber

Rescue from car stuck in snow drift

Aid to authorities during blizzard

Incidents found while on exercise

Callouts reason not stated

Total

1

90

62

3
2

2
1
1

Table 2 Medical problems in casualties (excluding those dead when found)

\begin{tabular}{ll}
\hline & No of casualties \\
\hline $\begin{array}{l}\text { Cold exhaustion and cold stress (without } \\
\text { other problem) }\end{array}$ & 153 (in 48 \\
Exhaustion & incidents) \\
Heat exhaustion & 2 \\
Leg injuries & \\
$\quad$ Ankle fracture & 2 \\
Soft tissue injury ankle & 11 (2 had cold \\
Soft tissue knee injury & exhaustion) \\
& 4 (1 had \\
Fracture neck of femur & exhaustion) \\
Leg fracture unspecified & 1 \\
Soft tissue injury leg unspecified & 3 \\
Total leg injuries & 3 \\
Fracture spine (spondylolysis L5) & 23 \\
Soft tissue injury back & 1 \\
Soft tissue injuries neck and hip (and cold & 1 \\
stress) & 1 \\
Heat injury & 1 \\
Facial lacerations & 1 \\
Frostbite & 2 \\
Injuries unspecified & 1 \\
Medical problems & \\
Cardiac arrest (resuscitation attempted) & 1 \\
Benzodiazepine overdose and cold stress & 1 \\
Abdominal cramps (and cold & 1 \\
exhaustion) & \\
Dysmenorrhoea and cold stress & 1 \\
Gastroenteritis & 1 \\
Epileptic fit & 1 \\
Asthma & 1 \\
Severe depression & 1 \\
Pains in legs unspecified (probably & \\
cramps) & 1 \\
\hline & \\
& \\
&
\end{tabular}


Table 3 Casualties known to have been admitted to hospital

\begin{tabular}{ll}
\hline Cold exhaustion & 5 \\
\hline Ankle fracture & 2 \\
fracture neck femur & 1 \\
Traumatic spondylolysis L5 & 1 \\
Frostbite and cold exhaustion & 1 \\
Benzodiazepine overdose and cold stress & 1 \\
Soft tissue injuries neck and hip (and cold stress) & 1 \\
severe depression & 1 \\
& 1 \\
Total & 13 \\
\hline
\end{tabular}

Table 4 Casualties treated on 10 Tors expeditions 1983-1992

\begin{tabular}{ll}
\hline Heat exhaustion & 17 \\
\hline Collapse/exhaustion & $10+$ \\
Cold exhaustion & many \\
Sprained ankle & 9 \\
Knee injury & 4 \\
Leg injury (unspecified) & 7 \\
Injury toes & 1 \\
Sprains/strains (unspecified) & $13+$ \\
Clinical forearm fracture & 1 \\
Abdominal symptoms, eg colic, vomiting & 4 \\
Blisters & $9+$ \\
Pain inside & 1 \\
Asthma & 1 \\
\hline
\end{tabular}

\section{Discussion}

The injuries and illnesses treated by an MRT, especially in a moorland area, are a minority of those which occur. Many casualties are helped off the hill by their companions and in good weather most of the rest can be rescued by helicopter. A moorland MRT is usually called out for searching, especially at night, and for casualty evacuation in adverse weather conditions when helicopters cannot operate.

Callouts tend to occur at weekends and in the evenings, as concern for a missing person may not be raised until darkness falls. The busiest time of year is in the spring, probably because of the many groups of inexperienced young people training for the Ten Tors expedition.

There are very few reports in medical journals on mountain rescue medicine. The Mountain Rescue Council collects statistics and publishes an annual report which includes details of the medical conditions treated by its affiliated teams in England and Wales (there are seperate organisations for Scotland and Northern Ireland). The conditions treated in $1993^{1}$ are summarised in table 5. The work of an MRT depends on its location, as the pattern of injuries and illness varies with the terrain and the popularity of the area. The Mountain Rescue Council figures are an amalgamation of figures from MRTs in mountainous areas such as the Lake District and North Wales and from teams covering lower hills and moorland.

It is clear that the medical problems dealt with by the DRG are very different from those listed in the Mountain Rescue Council statistics, ${ }^{1}$ as on moorland there is less potential for serious injury following falls. Only three incidents in this series involved rock climbers.

The largest number of casualties on Dartmoor were cold or exhausted, and these problems were sometimes complicated by other injuries or medical problems. The statistics
Table 5 Injuries treated by mountain rescue teams in England and Wales 1993

\begin{tabular}{ll}
\hline Lower leg injuries & 210 \\
\hline Upper leg injuries & 13 \\
Pelvic/spinal injuries & 13 \\
Chest injuries & 8 \\
Back injuries bruising & 14 \\
$\quad$ fracture & 3 \\
$\quad$ neck & 8 \\
Internal injuries & 2 \\
Arm/shoulder injuries & 54 \\
Head injuries & $54(6$ fatal $)$ \\
Multiple abrasions & 18 \\
Exhaustion & 17 \\
Hypothermia & $16(1$ fatal $)$ \\
Heart attack & 35 (10 fatal) \\
Drowning & 13 \\
\hline
\end{tabular}

sent to the Mountain Rescue Council describe most of these casualties as suffering from hypothermia. In many cases this was qualified by descriptions such as "severe" or "mild" but I have described them as suffering from cold exhaustion or cold stress (when exhaustion was not a feature), as hypothermia was rarely proved. Temperatures were not measured in the field and by the time they reached hospital most had core temperatures above $35^{\circ} \mathrm{C}$. Some may have been hypothermic when found and warmed up before arrival in hospital, but many may never have been truly hypothermic. However, the body will maintain its core temperature despite severe loss of total body heat ${ }^{2}$ and many of these casualties were ill with exhaustion and undoubted cold stress. The DRG has not been involved with any casualty who died of hypothermia, although deaths from hypothermia in British hills are well described, ${ }^{3}$ and publicity surrounding the death of two Army cadets on Dartmoor in 1967 was a contributory factor to the formation of the DRG the following year.

Much emphasis is rightly given to the prevention and treatment of hypothermia and cold exhaustion, but heat exhaustion can also occur. This is not normally thought of as a problem on British hills but is well described in marathon and fun runners. ${ }^{4}$ Walkers and especially participants in organised events carrying heavy rucksacks should be warned of the possibility of heat exhaustion and advised on its prevention. ${ }^{5}$ It is distressing to find victims of heat exhaustion on a hot day under a cloudless sky putting on extra clothing and climbing into sleeping bags as they assumed that their symptoms were due to hypothermia which was the only environmental hazard they had been taught about.

As in the Mountain Rescue Council statistics, the commonest injuries treated by the DRG were to the lower leg. Other injuries and medical problems are uncommon and moorland rescue teams do not need to carry the drugs and equipment which may be used by rescue teams in popular mountain areas. ${ }^{6}$ However the DRG has, over the years, had to deal with a wide variety of conditions, often a long way from a road and with difficulty in obtaining advice because of poor radio communications, so good first aid training for members is essential. 
I would like to thank Dr R Beck, past honorary general secretary of the DRG, for allowing me access to the group's records.

1 Mountain Rescue Committee. Mountain and cave rescue. Ulverston, Cumbria: Mountain Rescue Committee, 1994

2 Lloyd EL. Hypothermia and cold stress. London: Croom

Helm, 1986.

3 Pugh LGCE. Accidental hypothermia in walkers, climbers and campers: report to the Medical Commission on Accident Prevention. BMF 1966;I:123-9.

4 Nicholson MR, Somerville KW. Heat stroke in a "run for fun". BMF 1978;ii:1525-6.

Consensus conference. Popular marathons, half marathons, and other long distance runs: recommendations for medical support. BMF 1984;288:1355-9.

6 Ellical 1 . cue. $\mathcal{F}$ Br Assoc Immed Care 1992;15:19-22.

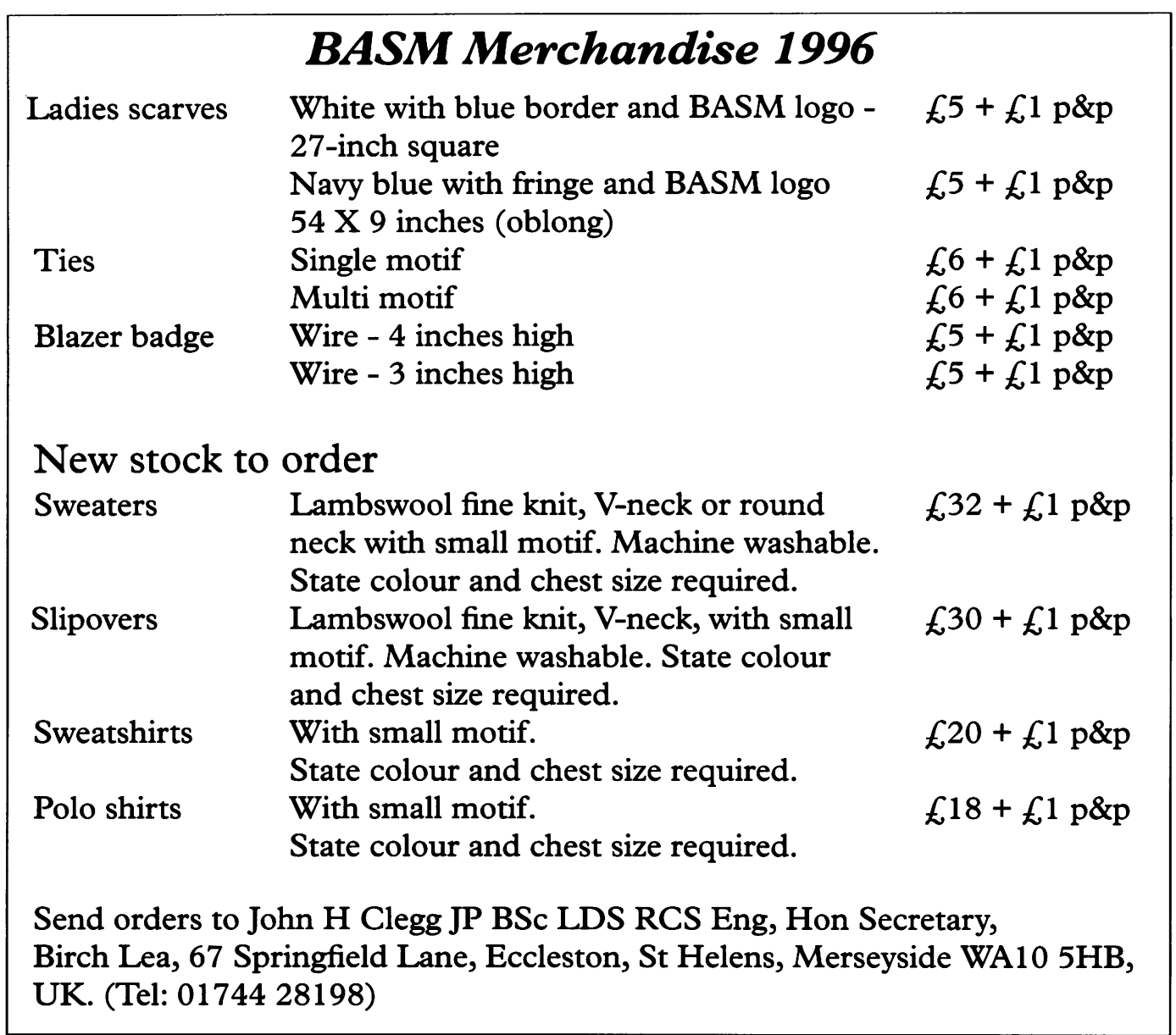

